\title{
Randomized Phase 2b Trial of Tofacitinib (CP-690,550) in De Novo Kidney Transplant Patients: Efficacy, Renal Function and Safety at 1 Year
}

\author{
F. Vincenti $i^{a, *}$, H. Tedesco Silva ${ }^{b}$, S. Busque ${ }^{c}$, \\ P. O'Connell ${ }^{d}$, J. Friedewald ${ }^{\mathrm{e}}$, D. Cibrik ${ }^{\mathrm{f}}$, \\ K. Budde ${ }^{g}$, A. Yoshida' ${ }^{\text {h }}$ S. Cohney', W. Weimar', \\ Y. S. Kimk', N. Lawendy', S.-P. Lan', E. Kudlacz', \\ S. Krishnaswami' and G. Chan' \\ aniversity of California, San Francisco, CA \\ b Hospital do Rim e Hipertensão, São Paulo, Brazil \\ ' Stanford University, Stanford, CA \\ 'Westmead Hospital, Sydney, Australia \\ e Northwestern University, Chicago, IL \\ ${ }^{f}$ University of Michigan, Ann Arbor, MI \\ ${ }^{g}$ Charité Universitätsmedizin, Berlin, Germany \\ h Henry Ford Hospital, Detroit, MI \\ 'Royal Melbourne Hospital, Melbourne, Australia \\ 'Erasmus Medisch Centrum, Rotterdam, The Netherlands \\ k Seoul National University College of Medicine, Seoul, \\ Korea \\ 'Pfizer Inc., Groton, CT \\ *Corresponding author: Flavio Vincenti, \\ Flavio.Vincenti@ucsfmedctr.org
}

In this Phase 2b study, 331 low-to-moderate risk de novo kidney transplant patients (approximately $60 \%$ deceased donors) were randomized to a more intensive (MI) or less intensive (LI) regimen of tofacitinib (CP-690, 550), an oral Janus kinase inhibitor or cyclosporine (CsA). All patients received basiliximab induction, mycophenolic acid and corticosteroids. Primary endpoints were: incidence of biopsy-proven acute rejection (BPAR) with a serum creatinine increase of $\geq 0.3 \mathrm{mg} / \mathrm{dL}$ and $\geq 20 \%$ (clinical BPAR) at Month 6 and measured GFR at Month 12. Similar 6-month incidences of clinical BPAR $(11 \%, 7 \%$ and $9 \%)$ were observed for MI, LI and CsA. Measured GFRs were higher ( $p<0.01$ ) at Month 12 for $\mathrm{MI}$ and $\mathrm{LI}$ versus CsA (65 mL/min, $65 \mathrm{~mL} / \mathrm{min}$ vs. $54 \mathrm{~mL} / \mathrm{min}$ ). Fewer ( $p<0.05$ ) patients in MI or LI developed chronic allograft nephropathy at Month 12 compared with CsA $(25 \%, 24 \%$ vs. $48 \%)$. Serious infections developed in $45 \%, 37 \%$ and $25 \%$ of patients in $\mathrm{MI}$, $\mathrm{LI}$ and CsA, respectively. Anemia, neutropenia and posttransplant lymphoproliferative disorder occurred more frequently in MI and LI compared with CsA. Tofacitinib was equivalent to CsA in preventing acute rejection, was associated with improved renal function and less chronic allograft histological injury, but had side-effects at the doses evaluated.
Key words: cyclosporine, kidney, renal function, tofacitinib

Abbreviations: $A U C_{0-12}, 0-12-h$ area under the plasma concentration-time curve; BID, twice daily; BPAR, biopsy-proven acute rejection; CAN, chronic allograft nephropathy; cg, allograft glomerulopathy; CMV, cytomegalovirus; CNI, calcineurin inhibitor; CsA, cyclosporine; cv, vascular fibrous intimal thickening; DGF, delayed graft function; EBV, Epstein-Barr virus; IF, interstitial fibrosis; IFG, impaired fasting glycemia; JAK, Janus kinase; K-M, Kaplan-Meier; LI, less intensive tofacitinib; LOCF, last observation carried forward; M, Months; MDRD, Modification of Diet in Renal Disease; MI, more intensive tofacitinib; MMF, mycophenolate mofetil; MPA, mycophenolic acid; NK, natural killer; NODAT, new-onset diabetes after transplantation; PRA, panel-reactive antibody; PTLD, posttransplant lymphoproliferative disorder; TA, tubular atrophy; TWC2, time-weighted average concentrations at $2 \mathrm{~h}$ postdose during the first 6 months.

Received 17 January 2012, revised 06 April 2012 and accepted for publication 17 April 2012

\section{Introduction}

The incidence of acute rejection in kidney transplant patients has fallen progressively without a proportionate increase in long-term allograft survival (1). Calcineurin inhibition remains the cornerstone of posttransplant immunosuppressive protocols. Long-term use of calcineurin inhibitors (CNIs) has been associated with chronic nephrotoxicity (2), prompting interest in $\mathrm{CNI}$-free regimens. However, CNI-free protocols have been hampered by unacceptably high rates of acute rejection (3-5) and other side effects (6).

Tofacitinib (CP-690,550) is an oral Janus kinase (JAK) inhibitor that suppresses intracellular signal transduction of multiple cytokines, including IL-2, IL-4, IL-7, IL-9, IL-15 and IL-21, which are essential for homeostasis and function of $T$ cells, B cells and natural killer (NK) cells. A small pilot study with tofacitinib showed promise in preventing acute rejection in kidney allografts (7). The current study was conducted to evaluate the efficacy and safety of tofacitinib when combined with basiliximab induction, mycophenolic 
acid (MPA) and corticosteroids in de novo kidney transplant patients.

\section{Methods}

\section{Patients}

Patients were immunologically low-to-moderate-risk recipients of primary kidney allografts from deceased donors or HLA-mismatched living donors. Key exclusion criteria were current panel-reactive antibody (PRA) $>30 \%$ or peak PRA $>50 \%$, positive B cell crossmatch, or pretransplant donorspecific anti-HLA antibodies. Allografts from extended-criteria donors and cardiac-death donors were excluded.

\section{Study design}

This was a randomized, multicenter, Phase $2 \mathrm{~b}$ study (ClinicalTrials.gov identifier NCT00483756) conducted in 57 centers in 15 countries. The trial was approved by the Institutional Review Boards and/or Independent Ethics Committees at each of the investigational centers participating in the study or a central IRB. It was conducted in compliance with the Declaration of Helsinki and the International Conference on Harmonisation Good Clinical Practice Guidelines. All patients provided written informed consent.

Following kidney transplantation, patients were randomized 1:1:1 to one of two tofacitinib regimens or cyclosporine (CsA) microemulsion (Novartis, Basel, Switzerland). A computer generated randomization schedule was used to assign patients to treatment groups and randomization was stratified with respect to donor source. In the more intensive (MI) tofacitinib group, patients received tofacitinib $15 \mathrm{mg}$ twice daily (BID) in Months 1-6, then $10 \mathrm{mg}$ BID in Months 7-12. In the less intensive (LI) tofacitinib group, patients received tofacitinib $15 \mathrm{mg}$ BID in Months 1-3, then $10 \mathrm{mg} \mathrm{BID}$ in Months 4-12. Patients and investigators were blinded to the assignment to $\mathrm{MI}$ versus $\mathrm{LI}$ but were aware of assignment to tofacitinib versus CsA. In the control group, CsA was started at $8-10 \mathrm{mg} / \mathrm{kg} /$ day and adjusted to achieve 12-h trough whole blood levels of $125-400 \mathrm{ng} / \mathrm{mL}$ in Months $1-3$ and $100-300 \mathrm{ng} / \mathrm{mL}$ in Months 4-12.

All patients received basiliximab induction $(20 \mathrm{mg}$ intravenously on Days 0 and 4), MPA products at an initial dose of $2 \mathrm{~g} /$ day mycophenolate mofetil (MMF), or $1.44 \mathrm{~g} /$ day enteric-coated MPA, and corticosteroids through at least Month 12. Cytomegalovirus (CMV) prophylaxis was required for 3 months in CMV-seronegative recipients of kidneys from CMV-seropositive donors, while other donor-recipient CMV combinations received prophylaxis according to local practice. GFR was measured at Months 6 and 12 by determining iohexol serum clearance. Protocol biopsies of the allograft were required at the time of implantation and Month 12. Patients underwent periodic monitoring of Epstein-Barr virus (EBV) load in whole blood and BK virus load in plasma according to the protocol. Patients who completed 12 months of treatment were eligible for a long-term extension study.

\section{Blinding}

The investigator and patient were aware of the treatment assignment if the patient was randomized to the control arm (CsA) but were blinded to assignment to $\mathrm{MI}$ versus $\mathrm{LI}$ if the patient was randomized to tofacitinib. Patients in the tofacitinib arms received the same dose during the first 3 months $(15 \mathrm{mg} \mathrm{BID})$ and after Month $6(10 \mathrm{mg} \mathrm{BID})$ : therefore, the blinding period was limited to Months $4-6$, during which time patients in the $\mathrm{MI}$ group received $15 \mathrm{mg} \mathrm{BID}$ and patients in the LI group received 10 mg BID. During Months 4-6, each patient randomized to tofacitinib received three bottles of identical appearance containing tofacitinib $5 \mathrm{mg}$ tablets or matching placebo. The patient was instructed to take one tablet from each bottle in the morning and in the evening.

\section{Efficacy and safety endpoints}

The primary efficacy endpoint was the incidence of first clinical biopsyproven acute rejection ("clinical BPAR") at Month 6. To meet this endpoint, the patient must have had BPAR and an increase in serum creatinine of $\geq 0.3 \mathrm{mg} / \mathrm{dL}$ and $\geq 20 \%$ from the prerejection baseline. The other primary endpoint was measured GFR at Month 12. Allograft biopsies were reviewed by a central pathologist. A separate secondary endpoint of "total BPAR" was also analyzed based on the central pathologist's finding of acute/active cellular rejection or antibody-mediated rejection according to the Banff 2003 classification (8), regardless of clinical evidence of changes in renal function. All for-cause, surveillance, and protocol biopsies were included in the assessment for total BPAR.

Secondary endpoints included total BPAR rate at Months 6 and 12, estimated GFR at Month 12 calculated from the Modification of Diet in Renal Disease (MDRD) (9) and Nankivell (10) equations, chronic allograft lesions at Month 12, and adverse events. New-onset diabetes after transplantation (NODAT) was defined as the need for treatment of hyperglycemia for $\geq 30$ consecutive days or fasting serum glucose $\geq 126 \mathrm{mg} / \mathrm{dL}$. Impaired fasting glycemia was defined as fasting serum glucose $110-125 \mathrm{mg} / \mathrm{dL}$. Stage- 1 hypertension was defined as systolic blood pressure $140-159 \mathrm{mmHg}$ or diastolic blood pressure $90-99 \mathrm{mmHg}$.

\section{Drug exposure and exposure-response analyses}

The 0-12-h area under the plasma concentration-time curve $\left(\mathrm{AUC}_{0-12}\right)$ of MPA at steady state was ascertained using population pharmacokinetics from 2476 MPA concentrations from 276 patients who received tofacitinib or CsA

Prespecified exploratory exposure-response analyses were performed to evaluate the relationship between tofacitinib exposure and clinical events. Individual tofacitinib exposure was measured as time-weighted average concentrations at $2 \mathrm{~h}$ postdose (TWC2). TWC2 was calculated by dose normalizing and averaging individual 2-h concentrations over the first 6 months, and recalculating the 2-h concentration for the assigned dose (10 or $15 \mathrm{mg}$ BID) through Month 6.

\section{Statistical analyses}

All efficacy and safety analyses were based on the full analysis set, defined as patients who received at least one dose of study treatment. Primary analyses were performed to evaluate both noninferiority in the 6-month incidence of clinical BPAR and superiority in 12-month measured GFR between $\mathrm{MI}$ or $\mathrm{LI}$ and the CsA control group. The Hochberg multiple comparison procedure was used to test each tofacitinib group versus $\mathrm{Cs} A$, and a step-down procedure was used for evaluating the two primary endpoints (clinical BPAR before measured GFR) at the overall one-sided type-l error level of $20 \%$. To meet the noninferiority criterion for 6-month clinical BPAR incidence, the upper one-sided $80 \%$ confidence limit of the difference (tofacitinib-CsA) had to be $<12 \%$. The noninferiority margin of $12 \%$ was chosen based on a literature review of the treatment effect of the CNIs and was applied to both clinical BPAR and total BPAR evaluations. A sample size of 100 patients per group would provide $81 \%$ power to declare noninferiority in the 6-month clinical BPAR rate and superiority in the 12-month measured GFR jointly between at least one of the tofacitinib groups and CsA.

Clinical BPAR and total BPAR data were evaluated using the Kaplan-Meie survival method. Measured GFR at Month 12 and estimated GFR were analyzed using a linear mixed-effects model for repeated measures as the primary analysis, with sensitivity analyses performed using last observation carried forward (LOCF) and imputation of graft loss or death as zero, where applicable. 
Figure 1: Patient disposition.

\section{Results}

\section{Patient disposition and demographics}

In total, 331 patients were randomized and 322 patients received study treatment (106 in $\mathrm{Ml}, 107$ in $\mathrm{LI}$ and 109 in CsA; Figure 1). These patients were randomized from 13 February 2008 to 27 February 2009. Baseline characteristics were similar among the treatment groups (Table 1). More patients discontinued $\mathrm{MI}$ and $\mathrm{LI}$ than CsA prior to Month 12 (43.4\% vs. $44.9 \%$ vs. $28.4 \%$, respectively). A similar proportion of patients in each group discontinued due to lack of efficacy, but more patients in $\mathrm{Ml}$ and $\mathrm{LI}$ discontinued because of infection or hematological abnormalities (Figure 1).

\section{Acute rejection}

The primary efficacy endpoint of 6-month incidence of clinical BPAR met noninferiority criterion for both $\mathrm{MI}$ and $\mathrm{LI}$ when compared with CsA $111.4 \%$ and $7.1 \%$ vs. 9.0\%; Table 2; Figure 2, panel A). Similarly, the 6- and 12-month incidences of total BPAR for $\mathrm{MI}$ and $\mathrm{LI}$ were noninferior to CsA (Table 2; Figure 2, panel C). No clinically meaningful difference was observed between either $\mathrm{MI}$ or $\mathrm{LI}$ and CsA in the 12-month incidence of total BPAR in deceased donors or living donors, or severe cellular rejections (grade IIB or (II). Antibody-mediated rejection of grade II or higher was observed in the CsA group only. Locally diagnosed and treated acute rejection was not more frequent in $\mathrm{Ml}$ or LI compared with the CsA group. More black patients developed acute rejection while receiving tofacitinib compared with CsA but the difference did not reach statistical significance.

\section{Renal function}

The co-primary endpoint of measured GFR was significantly higher $(\mathrm{p}<0.01)$ at Month 12 in $\mathrm{Ml}$ and $\mathrm{LI}$ than CsA $(64.6 \mathrm{~mL} / \mathrm{min}$ vs. $64.7 \mathrm{~mL} / \mathrm{min}$ vs. $53.9 \mathrm{~mL} / \mathrm{min}$, respectively; Table 3; Figure 2, panel B). This was also observed at Month 6. Similarly, estimated GFR values for MI and $\mathrm{LI}$ calculated from the MDRD and Nankivell equations were significantly higher than CsA at Months 6 and 12 . Sensitivity analyses of estimated GFR based on LOCF and imputation of graft loss or death as zero supported these results. The higher estimated GFR values in $\mathrm{MI}$ and $\mathrm{LI}$ were observed as early as 1 month posttransplant and persisted through Month 12 (Figure 2, panel D).

\section{Chronic allograft damage}

At Month 12, significantly fewer $(\mathrm{p}<0.05)$ patients in $\mathrm{MI}$ or $\mathrm{LI}$ developed chronic allograft nephropathy (CAN) according to the Banff 2003 criteria compared with CsA (Table 3). In particular, fewer patients in $\mathrm{Ml}$ or $\mathrm{LI}$ developed grade-II or grade-III CAN. When Month 12 protocol biopsies were compared with implantation biopsies, fewer patients in $\mathrm{Ml}$ or LI showed progression (increase in CAN grade or Banff chronicity score). With regard to the individual Banff chronic lesion scores, a significantly lower proportion of patients showed an increase in ci (interstitial fibrosis [IF]) and/or ct (tubular atrophy [TA]) scores in the tofacitinib groups (Table 3).

\section{Patient and allograft survival}

No statistically significant difference in patient survival was observed between either $\mathrm{MI}$ or LI and CsA (96.4\% [MI] and $96.6 \%$ [LI] vs. 96.9\% [CsA]; Table 2). Infection was implicated as the cause of death in six of eight patients. 
Tofacitinib in Kidney Transplant Patients

Table 1: Baseline characteristics, demography and concomitant immunosuppressant dosage

\begin{tabular}{|c|c|c|c|}
\hline & $\mathrm{MI}(\mathrm{N}=106)$ & $\mathrm{LI}(\mathrm{N}=107)$ & CsA $(N=109)$ \\
\hline \multicolumn{4}{|l|}{ Recipient } \\
\hline Age, years, mean (SD) & $47.8(12.1)$ & 45.8 (12.6) & 47.1 (12.9) \\
\hline Male, n (\%) & $82(77.4)$ & $80(74.8)$ & $70(64.2)$ \\
\hline \multicolumn{4}{|l|}{ Race } \\
\hline White, n (\%) & $66(62.3)$ & $71(66.4)$ & $78(71.6)$ \\
\hline Black, n (\%) & $16(15.1)$ & $21(19.6)$ & $12(11.0)$ \\
\hline Other, n (\%) & $24(22.6)$ & $15(14.0)$ & $19(17.4)$ \\
\hline \multicolumn{4}{|l|}{ HLA-mismatch, mean (SD) } \\
\hline Deceased donors & $3.1(1.9)$ & $3.1(2.0)$ & $3.4(1.7)$ \\
\hline Living donors & $3.9(1.5)$ & $3.9(1.4)$ & $3.6(1.3)$ \\
\hline CMV D+R-, n (\%) & $17(16.0)$ & $16(15.0)$ & $10(9.2)$ \\
\hline Negative recipient EBV serostatus, $\mathrm{n}(\%)$ & $7(6.6)$ & $6(5.6)$ & $9(8.3)$ \\
\hline Diabetic pretransplant, $\mathrm{n}(\%)$ & $21(19.8)$ & $25(23.4)$ & $25(22.9)$ \\
\hline On dialysis pretransplant, $\mathrm{n}(\%)$ & $100(94.3)$ & $99(92.5)$ & $99(90.8)$ \\
\hline \multicolumn{4}{|l|}{ Donor } \\
\hline Deceased, n (\%) & $65(61.3)$ & $65(60.7)$ & $67(61.5)$ \\
\hline Black, n (\%) & $8(7.5)$ & $11(10.3)$ & $5(4.6)$ \\
\hline Age, years, mean $(S D)$ & $42(13)$ & $42(15)$ & $40(13)$ \\
\hline $\begin{array}{l}\text { Cold ischemic time (hours for deceased donors), } \\
\text { median (interquartile range) }\end{array}$ & $16.0(9.3-20.0)$ & $16.0(10.0-21.4)$ & $16.1(11.6-20.0)$ \\
\hline \multicolumn{4}{|l|}{ Concomitant immunosuppressant dosage (median) } \\
\hline MMF dose (g/day) at Month 6 & 1.5 & 2.0 & 2.0 \\
\hline MMF dose (g/day) at Month 12 & 1.5 & 1.5 & 2.0 \\
\hline Prednisone dose (mg/day) at Month 12 & 5 & 5 & 5 \\
\hline
\end{tabular}

$\mathrm{CMV}=$ cytomegalovirus; $\mathrm{CsA}=$ cyclosporine; $\mathrm{EBV}=$ Epstein-Barr virus; $\mathrm{LI}=$ less intensive tofacitinib; $\mathrm{MI}=$ more intensive tofacitinib; $\mathrm{MMF}=$ mycophenolate mofetil; PRA = panel-reactive antibody; SD = standard deviation.

Among surviving patients, graft failure occurred in two, five and one patients in the $\mathrm{MI}, \mathrm{LI}$ and CSA groups, respectively. In the LI group, technical complications (surgical complications or renal artery/vein thrombosis) accounted for three of five cases of graft failure. In another LI patient who discontinued tofacitinib after one day, graft failure occurred due to acute rejection approximately 9 months posttransplant.

\section{Safety and tolerability}

Adverse events occurring in $>10 \%$ of patients in any treatment group, and adverse events of special interest, are shown in Table 4. Serious infections and CMV disease (Figure 2, panel E) occurred more frequently in $\mathrm{Ml}$ and $\mathrm{LI}$ than in the CsA group. Fewer patients in $\mathrm{MI}$ or $\mathrm{LI}$ developed NODAT or impaired fasting glycemia (24.2\% [MI] and $17.8 \%$ [LI] vs. $38.2 \%$ [CsA]).

Malignancy developed in six patients in $\mathrm{Ml}$, one patient in $\mathrm{LI}$ and one patient in CsA. The six patients in $\mathrm{Ml}$ included three cases of solid malignancy likely to have been preexisting at the time of transplantation (one case each of renal cell carcinoma and prostate cancer that occurred within 3 months posttransplant, and one case of prostate cancer in a patient with elevated prostate surface antigen level at the time of transplantation). Posttransplant lymphoproliferative disorder (PTLD) developed in two patients in $\mathrm{Ml}$ and one patient in LI. After Month 12, two additional patients in the $\mathrm{Ml}$ group developed PTLD. Among the five patients who developed PTLD, four were EBV seropositive at the time of transplantation.

More patients had hemoglobin levels $<8$ or $<10 \mathrm{~g} / \mathrm{dL}$ in $\mathrm{MI}$ and $\mathrm{LI}$, and more patients had absolute neutrophil counts $<500$ or $<1000$ cells/ $\mu \mathrm{L}$ in $\mathrm{Ml}$ than in the CsA group (Table 4). Mean cell counts of CD3+ T cells and CD56+ NK cells were lower in $\mathrm{MI}$ and $\mathrm{LI}$ than CsA at Months 6 and 12 (Table 4).

At Month 12, total serum and LDL cholesterol levels were slightly higher in LI than in the CsA group, without a difference in the LDL/HDL ratio. However, lipid-lowering agents were used less frequently in the $\mathrm{LI}$ group. In $\mathrm{MI}$ and $\mathrm{LI}$, fewer patients had $\geq$ stage- 1 hypertension at Month 6, and fewer patients used $>2$ antihypertensive medications at Months 6 and 12 .

\section{Pharmacokinetics and exposure-response analysis}

Through Month 6, model-predicted MPA AUC $0-12$ was $37.4 \%$ higher (90\% confidence interval: $25.4,50.6 \%$ ) in the tofacitinib groups compared with the CsA group. Geometric mean (90\% confidence interval) model-predicted MPA AUC ${ }_{0-12}$ for MMF $1 \mathrm{~g}$ BID for the CsA group was 42.8 (39.0, 46.9) $\mathrm{mg} \mathrm{h} / \mathrm{L}$. Exposure-response analysis indicated that at tofacitinib TWC2 below the median $(125 \mathrm{ng} / \mathrm{mL})$, the 12-month incidences of total BPAR, serious infections, and $\mathrm{CMV}$ disease were comparable to those in the CsA group (Figure 2, panel F), whereas higher 
Vincenti et al.

Table 2: Efficacy, death and graft loss

\begin{tabular}{|c|c|c|c|c|c|c|}
\hline \multirow[b]{2}{*}{ Efficacy } & \multicolumn{2}{|c|}{$\mathrm{MI}(\mathrm{N}=106)$} & \multicolumn{2}{|c|}{$\mathrm{LI}(\mathrm{N}=107)$} & \multicolumn{2}{|c|}{$\mathrm{CsA}(\mathrm{N}=109)$} \\
\hline & Month 6 & Month 12 & Month 6 & Month 12 & \multirow{2}{*}{$\begin{array}{l}\text { Month } 6 \\
9(9.0)\end{array}$} & \multirow{2}{*}{$\frac{\text { Month } 12}{9(9.0)}$} \\
\hline $\begin{array}{l}\text { Patients with first clinical } \\
\text { BPAR, } \mathrm{n}(\%)^{1}\end{array}$ & $11(11.4)$ & $11(11.4)$ & $7(7.1)$ & $7(7.1)$ & & \\
\hline Difference $(60 \% \mathrm{Cl})$ & $2.5(-1.2,6.1)$ & $2.5(-1.2,6.1)$ & $-1.8(-5.1,1.5)$ & $-1.8(-5.1,1.5)$ & - & - \\
\hline Difference $(95 \% \mathrm{Cl})$ & $2.5(-6.0,11.0)$ & $2.5(-6.0,11.0)$ & $-1.8(-9.4,5.8)$ & $-1.8(-9.4,5.8)$ & - & - \\
\hline $\begin{array}{l}\text { Patients with first total } \\
\text { BPAR, } \mathrm{n}(\%)^{1}\end{array}$ & $16(16.1)$ & $17(17.4)$ & $12(12.4)$ & $14(15.4)$ & $18(17.7)$ & $19(18.8)$ \\
\hline Difference $(60 \% \mathrm{Cl})$ & $-1.7(-6.2,2.8)$ & $-1.4(-6.1,3.2)$ & $-5.4(-9.6,-1.1)$ & $-3.4(-8.0,1.3)$ & - & - \\
\hline \multirow[t]{2}{*}{ Difference $(95 \% \mathrm{Cl})$} & $-1.7(-12.1,8.7)$ & $-1.4(-12.2,9.3)$ & $-5.4(-15.3,4.6)$ & $-3.4(-14.2,7.4)$ & - & - \\
\hline & & Month 12 & \multicolumn{2}{|c|}{ Month 12} & \multicolumn{2}{|c|}{ Month 12} \\
\hline \multicolumn{2}{|c|}{ Total BPAR in deceased donor recipients, $\mathrm{n}(\%)^{1}$} & $7(11.8)$ & \multicolumn{2}{|c|}{$8(13.9)$} & \multicolumn{2}{|c|}{$10(16.4)$} \\
\hline \multicolumn{2}{|c|}{ Total BPAR in living donor recipients, $\mathrm{n}(\%)^{1}$} & $10(25.7)$ & \multicolumn{2}{|c|}{$6(18.0)$} & \multicolumn{2}{|c|}{$9(22.3)$} \\
\hline \multicolumn{2}{|c|}{ Total BPAR in black patients, $\mathrm{n}(\%)^{1}$} & $4(30.2)$ & \multicolumn{2}{|c|}{4 (29.5) } & \multicolumn{2}{|c|}{$1(8.3)$} \\
\hline \multicolumn{2}{|c|}{ Total BPAR: acute/active cellular rejection, $\mathrm{n}(\%)$} & $16(15.1)$ & & & $18(1$ & \\
\hline Grade IA & & $2(1.9)$ & & & $1(0$ & \\
\hline Grade IB & & $3(2.8)$ & & & $4(3$ & \\
\hline Grade IIA & & $7(6.6)$ & & & $8(7$ & \\
\hline Grade IIB & & $3(2.8)$ & & & $5(4$ & \\
\hline Grade III & & $1(0.9)$ & & & 0 & \\
\hline Total BPAR: antibody-medi & ed rejection, n (\%) & $2(1.9)$ & & & $5(4$ & \\
\hline Grade I & & $2(1.9)$ & & & $1(0$ & \\
\hline Grade II & & 0 & & & $4(3$ & \\
\hline Grade III & & 0 & & & 0 & \\
\hline $\begin{array}{l}\text { Patients with locally diagno } \\
\text { rejection (adverse event) }\end{array}$ & $\begin{array}{l}\text { ed and treated acute clinical } \\
(\%)^{1}\end{array}$ & $26(26.9)$ & & & $25(2$ & \\
\hline Black patients, $\mathrm{n}(\%)^{1}$ & & $4(28.2)$ & & & $2(1$ & \\
\hline Repeat rejection, $\mathrm{n}(\%)^{1}$ & & 0 & & & $4(4$ & \\
\hline Death & & Month 12 & & 12 & Montl & \\
\hline Patient survival at Month 1 & & 96.4 & & & 96. & \\
\hline Deaths within 12 months, & & 3 & & & 3 & \\
\hline Cause of death & & $\begin{array}{l}\text { - Pneumonia, sepsis } \\
\text { - Rhabdomyolysis, brain } \\
\text { edema } \\
\text { - Bronchopulmonary } \\
\text { aspergillosis, brain } \\
\text { infarction, aspiration } \\
\text { pneumonia }\end{array}$ & $\begin{array}{l}\text { - Cardiac } \\
\text { (electro } \\
\text { dissocia } \\
\text { - Broncho } \\
\text { aspergil }\end{array}$ & $\begin{array}{l}\text { st } \\
\text { hanical } \\
\text { ) } \\
\text { nonary } \\
\text { s }\end{array}$ & $\begin{array}{l}\text { - Sepsis, brair } \\
\text { - Pneumonia } \\
\text { - Peritonitis, }\end{array}$ & $\begin{array}{l}\text { infarction } \\
\text { psis }\end{array}$ \\
\hline Graft loss & & Month 12 & & 12 & Montl & \\
\hline Graft survival (death-censo & d) at Month $12, \%^{1}$ & 98.0 & & & 99. & \\
\hline Graft loss (excluding death) & t Month 12, n & 2 & & & 1 & \\
\hline Cause of graft loss & & & & & & \\
\hline Acute rejection & & - & & & - & \\
\hline Primary nonfunction & & 1 & & & - & \\
\hline Surgical complication & & - & & & - & \\
\hline Thrombosis & & 1 & & & 1 & \\
\hline
\end{tabular}

BPAR = biopsy-proven acute rejection; $\mathrm{Cl}=$ confidence interval; CsA = cyclosporine; $\mathrm{LI}=$ less intensive tofacitinib; $\mathrm{Ml}=$ more intensive tofacitinib. $\mathrm{n}=$ number of patients with condition.

${ }^{1}$ Kaplan-Meier estimates.

tofacitinib exposure was associated with evidence of overimmunosuppression or was associated with more infections and CMV. All five PTLD cases were associated with above-median tofacitinib TWC2s.

\section{Discussion}

The primary objectives of this study were to demonstrate noninferiority of tofacitinib over CsA in preventing acute rejection, and superiority of tofacitinib with respect to renal function. The rates of clinical BPAR and total BPAR in the three treatment arms fulfilled the prespecified criterion for noninferiority. The upper bounds of the 95\% confidence intervals of the difference between $\mathrm{Ml}$ or $\mathrm{LI}$ and CsA were also $<12 \%$ (Table 2). The total BPAR rate in the CsA group (17.7\% [Month 6] and 18.8\% [Month 12]) was consistent with the range reported in the literature $(11,12)$. Sub-group analyses did not reveal a higher rate of severe acute cellular rejection or humoral rejection in the tofacitinib groups.

The co-primary endpoint of measured GFR at Month 12 was significantly higher in both $\mathrm{Ml}$ and $\mathrm{LI}$ compared with CsA (64.6 [MI] and 64.7 [LI] vs. 53.9 [CsA] mL/min) 
A

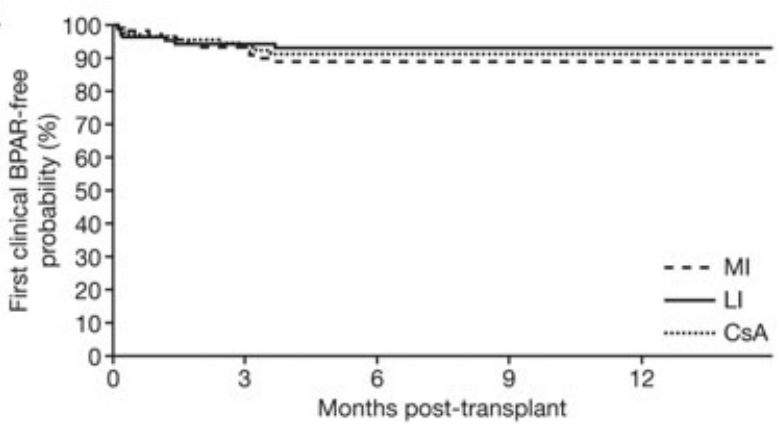

C

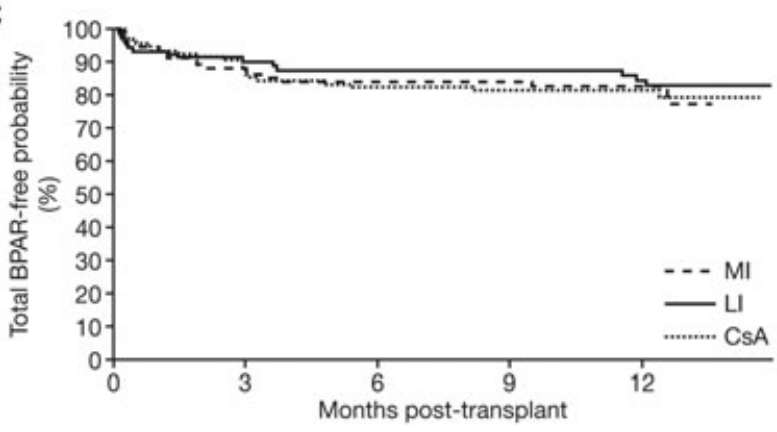

$\mathrm{E}$

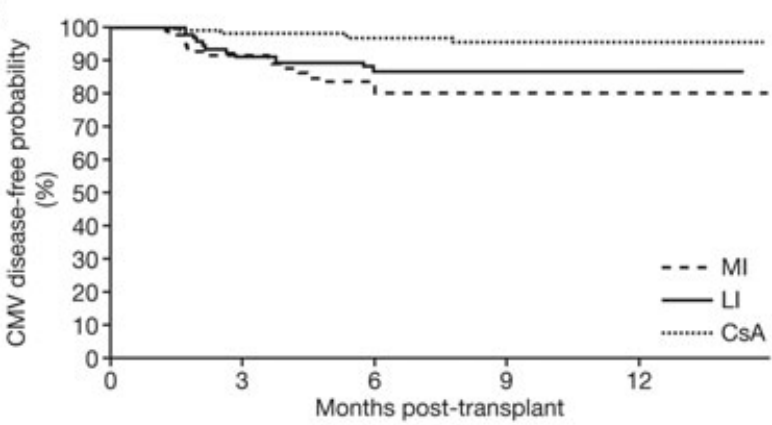

B

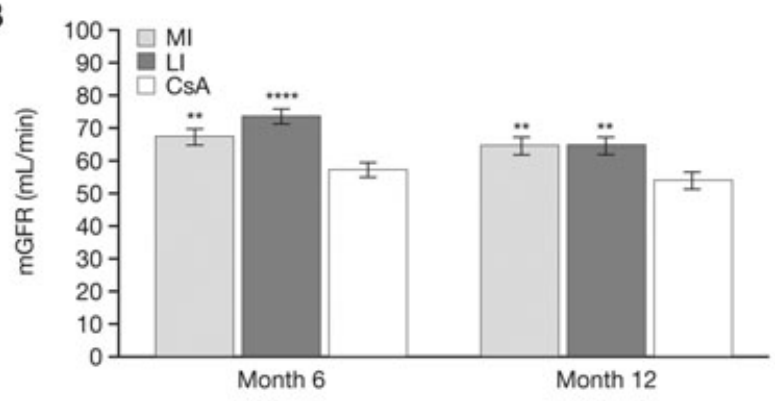

$" p<0.05 ; " * p<0.01 ; \cdots " p<0.001 ; \cdots \cdot \cdots p 0.0001$

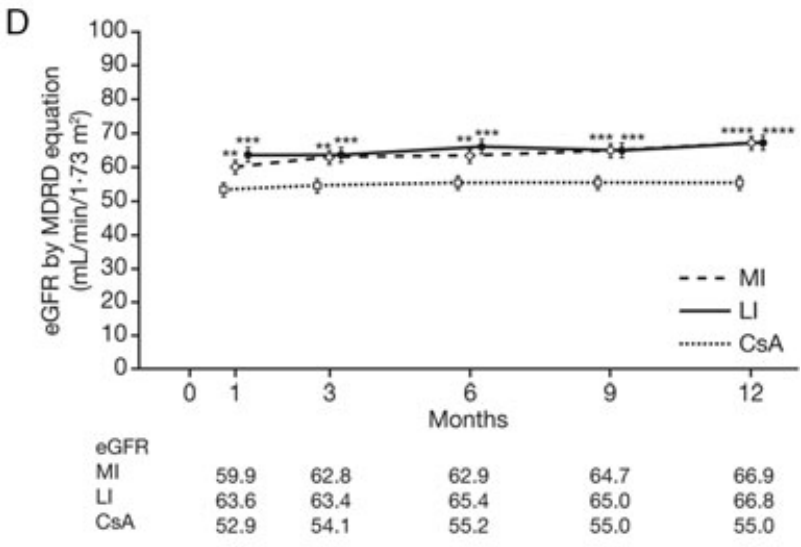

$" p<0.05 ; * p<0.01 ; \cdots p<0.001 ; \cdots p<0.0001$

$\mathrm{F}$

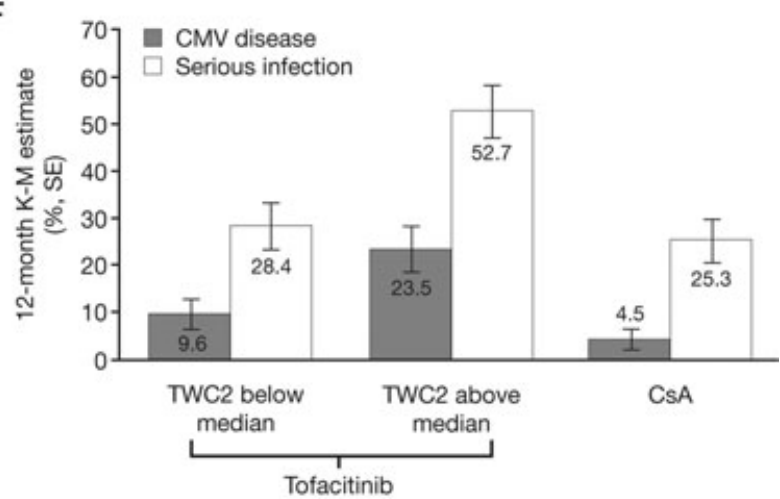

BPAR, biopsy-proven acute rejection; CMV, cytomegalovirus; CsA, cyclosporine; eGFR, estimated GFR; K-M, Kaplan-Meier;

$\mathrm{LI}$, less intensive tofacitinib; mGFR, measured GFR; MDRD, Modification of Diet in Renal Disease; MI, more intensive tofacitinib;

SE, standard error; TWC2, time-weighted average concentrations at 2 hours post-dose during the first 6 months.

Figure 2: (Panel A) K-M survival curves for clinical BPAR. (Panel B) Least squares means of measured GFR at Months 6 and 12. (Panel C) K-M survival curves for total BPAR. (Panel D) Least squares means of estimated GFR calculated by the MDRD equation versus time. (Panel E) K-M survival curves for CMV disease through Month 12. (Panel F) Exposure-response analyses indicated that at tofacitinib exposure below the median, the 12-month incidences of CMV disease and serious infection were comparable to those in the CsA group.

(Table 3). As GFR in CNI-treated kidney transplant patients typically declines by $1-2 \mathrm{~mL} / \mathrm{min} /$ year (13), the observed difference of approximately $10 \mathrm{~mL} / \mathrm{min}$ between the tofacitinib groups and CsA is of clinical relevance. One-year renal function has been correlated with graft survival (14), and improved renal function in the tofacitinib groups at Month 12 may prove advantageous for long-term graft outcome. 
Vincenti et al.

Table 3: Renal function and allograft histology

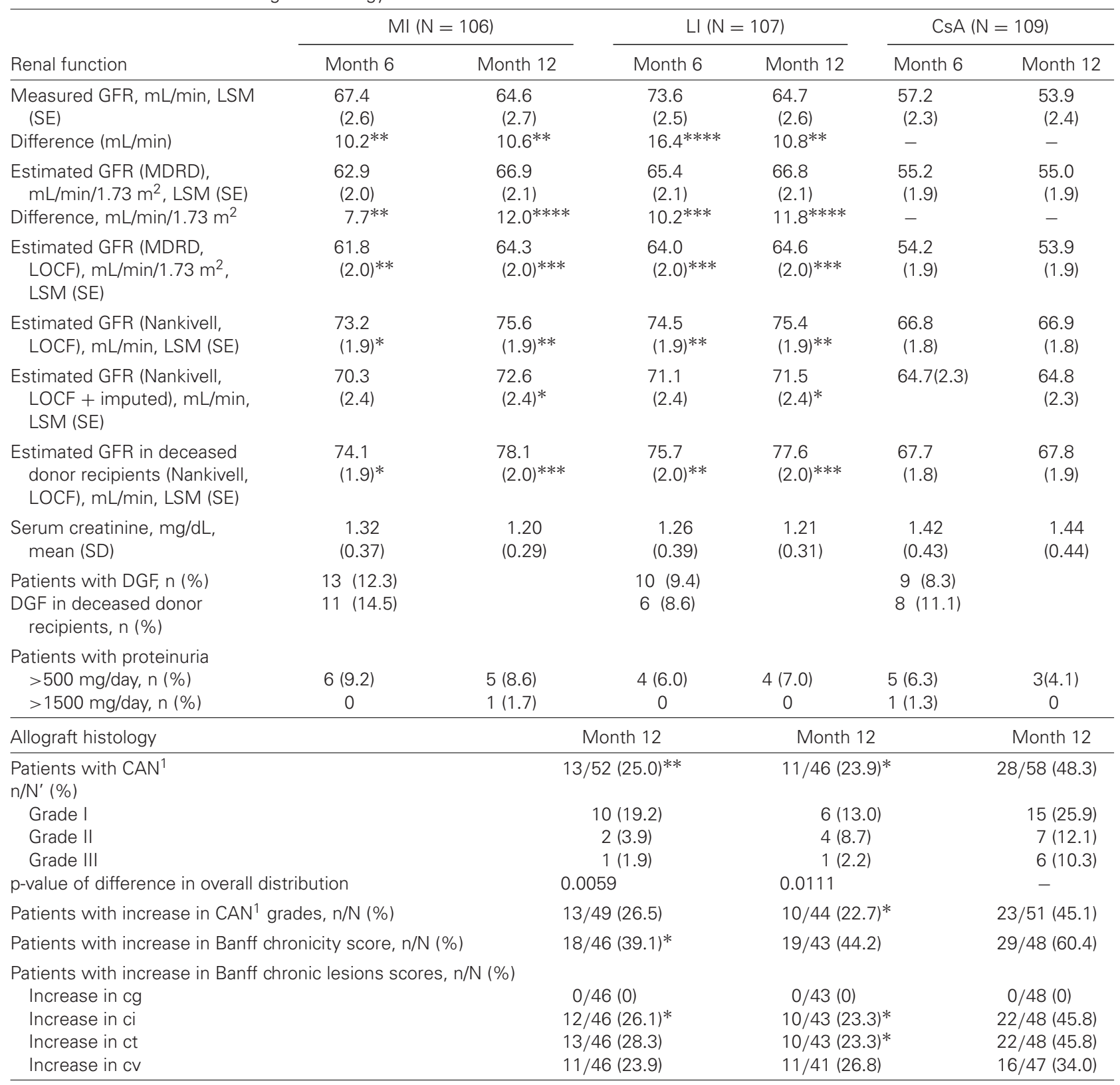

Notes: LSM (SE) is based on random effects linear model for repeated measures. $n$, number of patients with condition. $N$, number of patients with both implantation and Month 12 biopsies. N', number of patients with Month 12 biopsy.

${ }^{1}$ According to Banff 2003 criteria.

p-value versus CsA: ${ }^{*} p<0.05 ; * * p<0.01 ; * * p<0.001 ; * * * p<0.0001$; nominal $p$-values $\geq 0.05$ are considered not statistically significant.

$\mathrm{CAN}=$ chronic allograft nephropathy; $\mathrm{cg}=$ allograft glomerulopathy; $\mathrm{ci}=$ interstitial fibrosis; $\mathrm{Cs} \mathrm{A}=\mathrm{cyclosporine} ; \mathrm{ct}=$ tubular atrophy; $\mathrm{CV}=$ vascular fibrous intimal thickening; $\mathrm{DGF}=$ delayed graft function; GFR = glomerular filtration rate; $\mathrm{LI}=$ less intensive tofacitinib; LOCF = last observation carried forward; LSM = least squares mean; MDRD = Modification of Diet in Renal Disease; $\mathrm{MI}=$ more intensive tofacitinib; $\mathrm{SE}=$ standard error; $\mathrm{SD}=$ standard deviation.

The lower prevalence of CAN in both tofacitinib groups was consistent with the observed improvement in GFR. An increase in the prevalence of CAN from implantation to Month 12 was seen in all treatment groups but less in the tofacitinib groups. The between-group difference in pro- gression of allograft lesions from implantation to Month 12 was driven primarily by an increase in the severity of IF and TA, and to a lesser extent by an increase in arterial intimal thickening in the CsA group. This may indicate a long-term benefit from use of tofacitinib, as early tubulointerstitial 
Tofacitinib in Kidney Transplant Patients

Table 4: Safety

\begin{tabular}{|c|c|c|c|}
\hline & $\mathrm{MI}(\mathrm{N}=106)$ & $\mathrm{LI}(\mathrm{N}=107)$ & CsA $(N=109)$ \\
\hline \multicolumn{4}{|c|}{ Adverse events (all causality) occurring $>10 \%$ in any treatment group, $\mathrm{n}(\%)$} \\
\hline Anemia & $49(46.2)$ & $43(40.2)$ & $28(25.7)$ \\
\hline Leukopenia & $31(29.2)$ & $19(17.8)$ & $12(11.0)$ \\
\hline Neutropenia & $14(13.2)$ & $6(5.6)$ & $2(1.8)$ \\
\hline Abdominal distension & $6(5.7)$ & $8(7.5)$ & $11(10.1)$ \\
\hline Abdominal pain & $18(17.0)$ & $5(4.7)$ & $16(14.7)$ \\
\hline Constipation & $36(34.0)$ & $38(35.5)$ & $30(27.5)$ \\
\hline Diarrhea & $28(26.4)$ & $29(27.1)$ & $22(20.2)$ \\
\hline Nausea & $29(27.4)$ & $27(25.2)$ & $24(22.0)$ \\
\hline Vomiting & $17(16.0)$ & $13(12.1)$ & $19(17.4)$ \\
\hline Fatigue & $9(8.5)$ & $15(14.0)$ & $11(10.1)$ \\
\hline Edema & $15(14.2)$ & $11(10.3)$ & 12 (11.0) \\
\hline Edema peripheral & $25(23.6)$ & $19(17.8)$ & $30(27.5)$ \\
\hline Pyrexia & $21(19.8)$ & $17(15.9)$ & $14(12.8)$ \\
\hline Transplant rejection & $22(20.8)$ & $13(12.1)$ & $23(21.1)$ \\
\hline BK virus infection & $15(14.2)$ & 19 (17.8) & $6(5.5)$ \\
\hline CMV infection & $14(13.2)$ & $9(8.4)$ & $3(2.8)$ \\
\hline CMV viremia & $29(27.4)$ & $19(17.8)$ & $12(11.0)$ \\
\hline Urinary tract infection & $25(23.6)$ & $27(25.2)$ & $27(24.8)$ \\
\hline Upper respiratory tract infection & $17(16.0)$ & $9(8.4)$ & $17(15.6)$ \\
\hline Graft complication & 12 (11.3) & 17 (15.9) & $10(9.2)$ \\
\hline Incision-site pain & 9 (8.5) & $11(10.3)$ & $3(2.8)$ \\
\hline Procedural pain & $21(19.8)$ & $15(14.0)$ & $14(12.8)$ \\
\hline Blood creatinine increased & $17(16.0)$ & $20(18.7)$ & $20(18.3)$ \\
\hline Weight increased & $15(14.2)$ & $12(11.2)$ & $14(12.8)$ \\
\hline Fluid overload & $11(10.4)$ & $5(4.7)$ & $6(5.5)$ \\
\hline Hyperglycemia & $10(9.4)$ & $7(6.5)$ & $13(11.9)$ \\
\hline Hyperkalemia & $18(17.0)$ & $20(18.7)$ & $14(12.8)$ \\
\hline Hyperlipidemia & $10(9.4)$ & $10(9.3)$ & 13 (11.9) \\
\hline Hypocalcemia & $12(11.3)$ & $4(3.7)$ & $4(3.7)$ \\
\hline Hypokalemia & $13(12.3)$ & $11(10.3)$ & $3(2.8)$ \\
\hline Hypophosphatemia & $14(13.2)$ & $10(9.3)$ & $13(11.9)$ \\
\hline Back pain & 7 (6.6) & $12(11.2)$ & $4(3.7)$ \\
\hline Headache & $13(12.3)$ & $21(19.6)$ & $14(12.8)$ \\
\hline Tremor & $8(7.5)$ & $8(7.5)$ & $19(17.4)$ \\
\hline Insomnia & $6(5.7)$ & $10(9.3)$ & 13 (11.9) \\
\hline Dysuria & $13(12.3)$ & $8(7.5)$ & $8(7.3)$ \\
\hline Hematuria & $16(15.1)$ & $11(10.3)$ & $11(10.1)$ \\
\hline Cough & $16(15.1)$ & 7 (6.5) & 7 (6.4) \\
\hline Dyspnea & $11(10.4)$ & $9(8.4)$ & $7(6.4)$ \\
\hline Acne & $14(13.2)$ & $18(16.8)$ & $4(3.7)$ \\
\hline Rash & $12(11.3)$ & $6(5.6)$ & $7(6.4)$ \\
\hline Hypertension & $24(22.6)$ & $23(21.5)$ & $30(27.5)$ \\
\hline Hypotension & $18(17.0)$ & $13(12.1)$ & $7(6.4)$ \\
\hline \multicolumn{4}{|l|}{ AEs of special interest at Month $12, \mathrm{n}(\%)$} \\
\hline Serious infections ${ }^{1}$ & $37(44.5)^{* *}$ & $33(37.0)$ & $24(25.3)$ \\
\hline Clinically significant infection ${ }^{1}$ & $38(45.2)$ & $38(42.8)$ & $32(32.8)$ \\
\hline CMV disease (including CMV syndrome) ${ }^{1}$ & $16(19.5)^{* *}$ & $11(13.3)^{*}$ & $4(4.5)$ \\
\hline BK virus nephropathy ${ }^{1}$ & $2(2.6)$ & $3(3.9)$ & $1(1.1)$ \\
\hline Malignancy & $6(5.7)$ & $1(0.9)$ & $1(0.9)$ \\
\hline PTLD 1 & $2(3.1)$ & $1(1.6)$ & 0 \\
\hline NODAT ${ }^{1}$ & 7 (9.9) & $6(9.3)$ & $14(20.8)$ \\
\hline $\mathrm{IFG}^{1}$ & 10 (17.9) & $6(10.4)^{*}$ & 19 (28.6) \\
\hline NODAT/IFG ${ }^{1}$ & $15(24.2)$ & $11(17.8)^{*}$ & $26(38.2)$ \\
\hline
\end{tabular}

damage has been shown to predict long-term graft survival (15). Early-onset IF-TA may result from unchecked alloimmunity, chronic antibody-mediated rejection or direct $\mathrm{CNI}$ toxicity, though the relative contribution of these fac- tors continues to be debated and will vary between individuals (16-18). Similarly, the mechanism(s) through which tofacitinib is associated with less IF-TA is unknown, though the absence of $\mathrm{CNI}$ is likely to be a contributing factor. 
Vincenti et al.

Table 4: Continued.

\begin{tabular}{|c|c|c|c|c|c|c|}
\hline Laboratory and vital signs & Month 6 & Month 12 & Month 6 & Month 12 & Month 6 & Month 12 \\
\hline Hemoglobin, g/dL, mean (SD) & $12.0(1.8)$ & $12.9(1.7)$ & $12.2(1.5)$ & $12.9(1.4)$ & $12.6(1.7)$ & $13.0(1.5)$ \\
\hline $\begin{array}{l}\text { Patients with hemoglobin }<8 \\
\text { g/dL, } \mathrm{n}(\%)\end{array}$ & \multicolumn{2}{|c|}{$16(15.2)$} & \multicolumn{2}{|c|}{$11(10.6)$} & \multicolumn{2}{|c|}{$8(7.4)$} \\
\hline $\begin{array}{l}\text { Patients with hemoglobin }<10 \\
\text { g/dL, } \mathrm{n}(\%)\end{array}$ & \multicolumn{2}{|c|}{$68(64.8)$} & \multicolumn{2}{|c|}{$68(65.4)$} & \multicolumn{2}{|c|}{$55(50.9)$} \\
\hline $\begin{array}{l}\text { Absolute neutrophil count, } \\
\mathrm{K} / \mathrm{mm}^{3} \text {, mean (SD) }\end{array}$ & $4.0(2.3)$ & $4.0(1.9)$ & $3.6(2.4)$ & $3.8(1.7)$ & $4.2(1.9)$ & $4.3(2.2)$ \\
\hline $\begin{array}{l}\text { Patients with neutrophil } \\
\text { counts }<500 / \mathrm{mm}^{3}, \mathrm{n}(\%)\end{array}$ & \multicolumn{2}{|c|}{$4(3.8)$} & \multicolumn{2}{|c|}{$2(1.9)$} & \multicolumn{2}{|c|}{$2(1.9)$} \\
\hline $\begin{array}{l}\text { Patients with neutrophil } \\
\text { counts }<1000 / \mathrm{mm}^{3}, \mathrm{n}(\%)\end{array}$ & \multicolumn{2}{|c|}{$19(18.1)^{* * *}$} & \multicolumn{2}{|c|}{$4(3.8)$} & \multicolumn{2}{|c|}{$4(3.7)$} \\
\hline $\begin{array}{l}\text { Total WBC count, } \mathrm{K} / \mathrm{mm}^{3} \text {, } \\
\text { mean (SD) }\end{array}$ & $5.7(2.7)$ & $5.7(2.2)$ & $5.3(2.4)$ & $5.7(2.1)$ & $6.4(2.3)$ & $6.7(2.4)$ \\
\hline $\begin{array}{l}\text { Absolute lymphocyte count, } \\
\mathrm{K} / \mathrm{mm}^{3} \text {, mean (SD) }\end{array}$ & $1.1(0.6)$ & $1.1(0.5)$ & $1.2(0.5)$ & $1.2(0.6)$ & $1.6(0.7)$ & $1.7(0.6)$ \\
\hline $\begin{array}{l}\text { Absolute platelet count, } \\
\mathrm{K} / \mathrm{mm}^{3} \text {, mean (SD) }\end{array}$ & $265(107)$ & 246 (93) & $253(91)$ & $242(70)$ & $245(61)$ & $239(64)$ \\
\hline $\begin{array}{l}\text { Absolute CD3+ T cell count, } \\
\text { cells/ } \mu \mathrm{L} \text { mean (SD) }\end{array}$ & 812 (379) & 797 (369) & $970(410)$ & $956(522)$ & $1268(693)$ & $1353(648)$ \\
\hline $\begin{array}{l}\text { Absolute CD56+ NK cell } \\
\text { count, cells/ } \mu \mathrm{L} \text {, mean (SD) }\end{array}$ & $68(64)$ & $96(101)$ & $65(49)$ & 77 (58) & $170(123)$ & $169(123)$ \\
\hline $\begin{array}{l}\text { Total serum cholesterol, } \\
\mathrm{mg} / \mathrm{dL}, \mathrm{LSM}\end{array}$ & 201 & 195 & 204 & 209 & 200 & 194 \\
\hline $\begin{array}{l}\text { Serum LDL cholesterol, } \\
\text { mg/dL, LSM }\end{array}$ & 111 & 111 & 110 & 115 & 114 & 108 \\
\hline Serum LDL/HDL ratio, LSM & 2.3 & 2.2 & 2.4 & 2.3 & 2.4 & 2.2 \\
\hline $\begin{array}{l}\text { Patients who used } \\
\text { lipid-lowering drugs, n (\%) }\end{array}$ & $38(56.7)$ & $28(59.6)$ & $26(37.7)$ & $17(37.8)$ & $44(52.4)$ & 38 (55.9) \\
\hline $\begin{array}{l}\text { Patients with } \geq \text { stage-1 } \\
\text { hypertension, } \mathrm{n}(\%)\end{array}$ & $17(25.8)^{* * * *}$ & $21(35.6)$ & $26(37.7)$ & $20(33.9)$ & $39(48.8)$ & $32(41.6)$ \\
\hline $\begin{array}{l}\text { Patients who used >2 } \\
\text { anti-hypertensive } \\
\text { medications, n (\%) }\end{array}$ & $32(47.8)^{* *}$ & $24(51.1)^{*}$ & $38(55.1) *$ & $25(55.6)$ & $59(70.2)$ & $49(72.1)$ \\
\hline
\end{tabular}

${ }^{1}$ Kaplan-Meier estimates.

p-value versus CsA: *p $<0.05 ; * * p<0.01 ; * * * p<0.001 ; * * * * p<0.0001$.

$\mathrm{CMV}=$ cytomegalovirus; $\mathrm{CsA}=$ cyclosporine; IFG = impaired fasting glycemia; LI = less intensive tofacitinib; LSM = least squares mean; $\mathrm{MI}=$ more intensive tofacitinib; NODAT = new-onset diabetes after transplantation; PTLD = posttransplant lymphoproliferative disorder; $\mathrm{WBC}=$ white blood cell.

The main concerns identified with the tofacitinib regimens in this study were the increased rates of infection and PTLD. Beyond Month 12, two additional patients in the Ml group developed PTLD. These findings suggest an excessive level of immunosuppression with the regimens used in the study and correlated with elevated tofacitinib exposure. In this study, tofacitinib dose reduction was not permitted until Month 3 (LI) or Month 6 (MI). Among tofacitinib-treated patients, the incidence of CMV disease was reduced by approximately one-third by the use of ganciclovir/valganciclovir prophylaxis (data not shown). Exposure-response analysis indicated that belowmedian tofacitinib exposure was associated with a lower incidence of infection while providing comparable protection from total BPAR as compared to higher tofacitinib exposure.

The higher incidence of anemia and neutropenia in the tofacitinib groups in the early posttransplant period may be partly due to inhibition of JAK2, a tyrosine kinase that mediates hematopoiesis. It should be noted that, due to a lack of pharmacokinetic interaction between MPA and tofacitinib, MPA exposure was higher among tofacitinib-treated patients in the first 6 months posttransplant. A decrease of the mean MMF dose in tofacitinib-treated patients later posttransplant (1.5 g/day in $\mathrm{MI}$ and $\mathrm{LI}$ vs. $2.0 \mathrm{~g} /$ day in the CsA group at Month 12; Table 1) would have resulted in more comparable MPA exposure among the treatment groups. Indeed the elevated MPA exposure in tofacitinibtreated patients may have partly accounted for the efficacy of the $\mathrm{MI}$ and $\mathrm{LI}$ groups, as well as some adverse events, such as over-immunosuppression and hematological abnormalities. Compared with CsA, fewer patients in the tofacitinib groups experienced NODAT or impaired fasting glycemia, though this difference did not reach statistical significance. If confirmed, the lower diabetogenicity of a tofacitinib-based regimen will be important given the adverse impact of NODAT on patient and graft outcome (19). 
A potential limitation of this study is the use of a CsA-based control group. Tacrolimus is now the most frequently used $\mathrm{CNI}$ in kidney transplantation, largely attributable to the lower rates of acute rejection reported with tacrolimus. However, very low rejection rates can now be achieved with CsA (20), and recent studies with the microemulsion formulation of CsA have reported similar rejection rates compared with tacrolimus (21-24). Therefore, this study remains relevant to clinical practice. In addition, discontinuation rates were high in all three treatment groups, ranging from $28 \%$ in the CsA group to $44-45 \%$ in the tofacitinib groups. The discontinuation rate due to lack of efficacy was similar in each group, suggesting that the improved renal function in $\mathrm{Ml}$ and $\mathrm{LI}$ cannot be attributed to a bias in selecting nonrejecting patients.

The overall findings of this Phase $2 b$ study suggest that tofacitinib, when combined with MPA at conventional doses, is effective in preventing allograft rejection and has a beneficial effect on renal allograft function and parenchymal preservation. However, this result was achieved at the expense of hematological toxicity and over-immunosuppression as demonstrated by increased incidences of serious infection, opportunistic viral infection and PTLD. Exposure-response analyses have identified tofacitinib levels that are tentatively associated with lower infection risk without loss of efficacy. This suggests that adjustments to the tofacitinib regimens used in this study may permit the benefits of improved GFR and less CAN without over-immunosuppression, indicating the need for additional concentration-controlled studies to optimize tofacitinib-based immunosuppression in kidney transplant patients. Overall, this study suggests that tofacitinib has the potential to be used in a CNI-free regimen for the prevention of renal allograft rejection.

\section{Acknowledgments}

This research was sponsored by Pfizer Inc. Editorial support was provided by Gary Dever, PhD, and Karen Irving, PhD, at Complete Medical Communications and was funded by Pfizer Inc. The authors would like to thank the staff, patients and investigators involved in this study, as well as Wenjin Wang, PhD, and Manisha Lamba, PhD, of Pfizer Inc.

We gratefully acknowledge the contribution of the principal investigators from the A3921030 Study Group: Matthew Cooper, University of Maryland Medical Center; Venkat Ram Peddi, California Pacific Medical Center; Flavio Vincenti, University of California San Francisco Medical Center; Steven Marc Steinberg, California Institute of Renal Research; Jonathan Bromberg, Mount Sinai School of Medicine; Daniel Conlon Brennan, Washington University School of Medicine; Diane Marie Cibrik, University of Michigan Health System; Alexander Clark Wiseman, University of Colorado Health Sciences; Khalid M. H. Butt, Westchester Medical Center; Junaid Ahmed, LifeLink HealthCare Institute; Randal Detwiler, University of North Carolina; Youmin Wu, University of Arkansas for Medical Sciences; Shamkant Mulgaonkar, St Barnabas Medical Center; Atsushi Yoshida, Henry Ford Hospital; Alan H. Wilkinson, UCLA Kidney Transplant Research Center; Goran B. Klintmalm, Baylor University Medical Center; Herwig UIf,
Meier-Kriesche University of Florida; Stephan Busque, Stanford School of Medicine; Didier Mandelbrot, Beth Israel Deaconess Medical Center; Anil Kumar, Hahnemann University Hospital; Mark Dale Stegall, Mayo Clinic; Michael Jack Germain, Western New England Renal and Transplant Associates; John J. Friedewald, Northwestern University-Feinberg School of Medicine; J. Michael Millis, University of Chicago; Douglas James Nor man, Oregon Health \& Sciences University; Stanley C. Jordan, CedarsSinai Medical Center; Angello Lin, Medical University of South Carolina; Sanjay Kulkarni, Yale University School of Medicine; Allan Gilbert Murray, University of Alberta Hospital; Valter Duro Garcia, Irmandade da Santa Casa de Misericordia de Porto Alegre Hospital Dom Vicente Scherer; Helio Tedesco Silva, Hospital do Rim e Hipertensao; Federico Oppenheimer Salinas, Hospital Clinic Provincial de Barcelona; Jose Maria Grinyo, Boira Hospital Universitari De Bellvitge; Marco Castagneto, Universita' Cattolica del Sacro Cuore; Sergio Stefoni, Universitaria di Bologna; Anders Hartmann, Rikshospitalet-Radiumhospitalet HF; Magdalena Durlik, SPZOZ Szpital Kliniczny Dzieciatka Jezus Centrum Leczenia Obrazen; Marian Klinger, SPZOZ Akademicki Szpital Kliniczny im; Christophe Legendre, Hopital Necker; Magali Giral, CHU Nantes; Fernando Nolasco, Hospital Curry Cabral; Alfredo Mota, Hospitais da Universidade de Coimbra; Willem Weimar, Erasmus Medisch Centrum; Stefan Vitko, Institut Klinicke a Experimentalni Mediciny Transplantcentrum; Yves Vanrenterghem, Universitaire Ziekenhuizen Leuven; Daniel Abramowicz, Hopital Erasme/Nephrologie; Bjoern Nashan, Universitaetsklinikum Hamburg; Klemens Budde, Centrum 13 Medizinische Klinik; Lionel Rostaing, CHU Rangueil-Service de Néphrologie; Michele Kessler, CHRU de Nancy-Brabois; Josette Eris, Royal Prince Alfred Hospital; Philip O'Connell, Westmead Hospital; Graeme R. Russ, The Queen Elizabeth Hospital; Solomon Cohney, Royal Melbourne Hospital; John Kanellis, Monash Medical Centre; Duck Jong Han, Asan Medical Center; Yon Su Kim, Seoul National University Hospital; Yu Seun Kim, Yonsei University College of Medicine Severance Hospital.

\section{Disclosure}

The authors of this manuscript have conflicts of interest to disclose as described by the American Journal of Transplantation:

Dr. Vincenti has received grants from Pfizer Inc., Astellas, Novartis, Bristol-Myers Squibb, and Amgen.

Dr. Tedesco Silva has received grants from Pfizer Inc.; and has acted as a consultant for, and has received payment for lectures from Pfizer Inc., Novartis, and Bristol-Myers Squibb.

Dr. Busque has received grants from Novartis.

Dr. O'Connell has acted as a consultant for, and has received travel support from, Pfizer Inc.; is a member of the board for Novartis, Roche, Janssen-Cilag, and BristolMyers Squibb; and has received payment for lectures and travel support from Astellas.

Dr. Friedewald has no conflicts of interest.

Dr. Cibrik has acted as a consultant for Pfizer Inc., Novartis, and Tolera Therapeutics. 


\section{Vincenti et al.}

Dr. Budde has received a grant from Pfizer Inc; has acted as a consultant for Pfizer Inc., Novartis, Life Cycle Pharma, Bristol-Myers Squibb, Pfizer Inc., TCL Pharma, and Hexal; has provided expert testimony for Fitzpatrick, Cella, Harper and Scinto (on behalf of Novartis); and has received payment for lectures from Astellas, Novartis, LifeCycle Pharma, Wyeth, Pfizer Inc., Roche AG, Bristol-Myers Squibb, and Siemens.

\section{Dr .Yoshida has no conflicts of interest.}

Dr. Cohney has acted as a consultant and member of the board for Novartis and Wyeth; has received grants from Roche, Amgen, and Janssen-Cilag; and has received payment for lectures from Bristol-Myers Squibb and Roche.

Dr. Weimar has received grants from Pfizer Inc., Genzyme, Roche, and Novartis; has acted as a consultant for Novartis, Astellas, and Wyeth; and has received payment for lectures from Astellas.

\section{Dr. Kim has no conflicts of interest.}

Dr. Lawendy is an employee of Pfizer Inc. and holds stock/stock options in Pfizer Inc.

Dr. Lan is an employee of Pfizer Inc.

Dr. Kudlacz is an employee of Pfizer Inc. and holds stock/stock options in Pfizer Inc.

Dr. Krishnaswami is an employee of Pfizer Inc. and holds stock/stock options in Pfizer Inc.

Dr. Chan is an employee of Pfizer Inc., holds stock/stock options in Pfizer Inc., and has received travel support from Pfizer Inc.

This research was sponsored by Pfizer Inc.

\section{References}

1. Meier-Kriesche HU, Schold JD, Srinivas TR, Kaplan B. Lack of improvement in renal allograft survival despite a marked decrease in acute rejection rates over the most recent era. Am J Transplant 2004; 4: 378-383.

2. Nankivell BJ, Borrows RJ, Fung CL, O'Connell PJ, Allen RD, Chapman JR. The natural history of chronic allograft nephropathy. N Engl J Med 2003; 349: 2326-2333.

3. Flechner SM. Sirolimus in kidney transplantation indications and practical guidelines: De novo sirolimus-based therapy without calcineurin inhibitors. Transplantation 2009; 87: S1-S6.

4. Srinivas TR, Schold JD, Guerra G, Eagan A, Bucci CM, MeierKriesche HU. Mycophenolate mofetil/sirolimus compared to other common immunosuppressive regimens in kidney transplantation. Am J Transplant 2007; 7: 586-594.

5. Vincenti F, Ramos E, Brattstrom C, et al. Multicenter trial exploring calcineurin inhibitors avoidance in renal transplantation. Transplantation 2001; 71: 1282-1287.
6. Weir MR, Diekmann F, Flechner SM, et al. mTOR inhibition: The learning curve in kidney transplantation. Transpl Int 2010; 23: 447460.

7. Busque S, Leventhal J, Brennan DC, et al. Calcineurin-inhibitorfree immunosuppression based on the JAK inhibitor CP-690,550: A pilot study in de novo kidney allograft recipients. Am J Transplant 2009; 9: 1936-1945.

8. Racusen LC, Colvin RB, Solez K, et al. Antibody-mediated rejection criteria-An addition to the Banff 97 classification of renal allograft rejection. Am J Transplant 2003; 3: 708-714.

9. Levey AS, Bosch JP, Lewis JB, Greene T, Rogers N, Roth D. A more accurate method to estimate glomerular filtration rate from serum creatinine: A new prediction equation. Modification of Diet in Renal Disease Study Group. Ann Intern Med 1999; 130: 461470.

10. Nankivell BJ, Gruenewald SM, Allen RD, Chapman JR. Predicting glomerular filtration rate after kidney transplantation. Transplantation 1995; 59: 1683-1689.

11. Ekberg H, Tedesco-Silva $H$, Demirbas $A$, et al. Reduced exposure to calcineurin inhibitors in renal transplantation. $N$ Engl J Med 2007; 357: 2562-2575.

12. Silva $H T$, Jr., Yang $H C$, Abouljoud $M$, et al. One-year results with extended-release tacrolimus/MMF, tacrolimus/MMF and cyclosporine/MMF in de novo kidney transplant recipients. Am J Transplant 2007; 7: 595-608.

13. Gill JS, Tonelli M, Mix CH, Pereira BJ. The change in allograft function among long-term kidney transplant recipients. J Am Soc Nephrol 2003; 14: 1636-1642.

14. Hariharan S, McBride MA, Cherikh WS, Tolleris CB, Bresnahan $\mathrm{BA}$, Johnson CP. Post-transplant renal function in the first year predicts long-term kidney transplant survival. Kidney Int 2002; 62: 311-318.

15. Nankivell BJ, Fenton-Lee CA, Kuypers DR, et al. Effect of histological damage on long-term kidney transplant outcome. Transplantation 2001; 71: 515-523.

16. Gaston RS. Chronic calcineurin inhibitor nephrotoxicity: Reflections on an evolving paradigm. Clin J Am Soc Nephrol 2009; 4: 2029-2034.

17. Gaston RS, Cecka JM, Kasiske BL, et al. Evidence for antibodymediated injury as a major determinant of late kidney allograft failure. Transplantation 2010; 90: 68-74.

18. Yates PJ, Nicholson ML. The aetiology and pathogenesis of chronic allograft nephropathy. Transpl Immunol 2006; 16: 148-157.

19. Hjelmesaeth J, Hartmann A, Leivestad T, et al. The impact of early-diagnosed new-onset post-transplantation diabetes mellitus on survival and major cardiac events. Kidney Int 2006; 69: 588595.

20. Vincenti F, Charpentier B, Vanrenterghem $Y$, et al. A phase III study of belatacept-based immunosuppression regimens versus cyclosporine in renal transplant recipients (BENEFIT study). Am J Transplant 2010; 10: 535-546.

21. Goldfarb-Rumyantzev AS, Smith L, Shihab FS, et al. Role of maintenance immunosuppressive regimen in kidney transplant outcome. Clin J Am Soc Nephrol 2006; 1: 563-574.

22. Kaplan B, Schold JD, Meier-Kriesche HU. Long-term graft survival with neoral and tacrolimus: a paired kidney analysis. J Am Soc Nephrol 2003; 14: 2980-2984.

23. Opelz G, Dohler B. Influence of immunosuppressive regimens on graft survival and secondary outcomes after kidney transplantation. Transplantation 2009; 87: 795-802.

24. Vincenti F, Friman S, Scheuermann E, et al. Results of an international, randomized trial comparing glucose metabolism disorders and outcome with cyclosporine versus tacrolimus. Am J Transplant 2007; 7: 1506-1514.

American Journal of Transplantation 2012; 12: 2446-2456 